\title{
Healthcare disparities amongst vulnerable populations of Arabs and Jews in Israel
}

\author{
Efrat Shadmi ${ }^{1,2}$
}

\begin{abstract}
The complex nature of studying health and healthcare disparities in general, and in the context of the Israeli healthcare system in particular, is depicted in two recent IJHPR articles. The first examines Emergency Department (ED) waiting times in a tertiary children's hospital and the second examines disparities in the health care for people with schizophrenia of an ethnic-national minority. Contrary to other Israeli studies on wide disparities in health and healthcare, these studies show no disparities - ED waiting times did not differ among Arab and Jewish children and report no differences in performance of Hemoglobin A1C tests or in surgical interventions in patients with cardiovascular disease between Arabs and Jews with schizophrenia. Thus, the studies reflect areas of equitable health care delivery within the Israeli healthcare system.

Future studies should account for the fact that the phenomena of health and healthcare disparities is complex and should utilize rigorous methodologies to take into consideration the various factors that may affect the manifestation of differences amongst population groups. As a result, they may help detect disparities which may otherwise be missed.
\end{abstract}

Two recent Israel Journal of Health Policy Research articles depict the complex nature of studying health and healthcare disparities in general and in the context of the Israeli healthcare system in particular. Feldman and colleagues [1] studied ethnic differences in Emergency Department (ED) waiting times between Jewish and Arab children in a tertiary children's hospital in northern Israel. Gal and colleagues [2] compare health care for high cholesterol, diabetes and cardiovascular disease in Jews and Arabs with schizophrenia in a cohort of patients of the largest Israeli health care organization.

The two papers present an impressive platform for the study of ethnic disparities within vulnerable population groups, namely children [1] and patients with schizophrenia [2]. Both utilize large cohorts (>50,000 individuals) from data that was collected over a span of more than five years. Gal and colleagues [2] report that fewer annual visits to specialists were recorded for service users diagnosed with schizophrenia than among their counterparts, and among Arab-Israelis compared to

\section{Correspondence: eshadmi@univ.haifa.ac.il}

${ }^{1}$ Faculty of Social Welfare and Health Sciences, University of Haifa, Haifa, Israel

${ }^{2}$ Department of Health Policy Planning and the Clalit research Institute, Chief Physician Office, Clalit Health Services, Tel Aviv, Israel
Jewish-Israelis. No differences were found in performance of Hemoglobin A1C tests or in surgical interventions in patients with cardio vascular disease between Arabs and Jews. Feldman and colleagues [1] show that ED waiting times did not differ among Arab and Jewish children. Moreover, their study showed that ethnic concordance between patients and the ED's triage nurses was not significantly associated with waiting times.

These findings should be evaluated in light of the multifaceted makeup of the Israeli society and its healthcare system, within a comprehensive approach that accounts for the various types of interrelated social determinants of health [3] and the complexity of health [4]. In Israel, Arabs constitute the largest minority group, which comprises about $20 \%$ of the population [5]. Arabs in Israel have been shown to present poorer healthcare utilization patterns and worse health outcomes in a wide variety of clinical domains. Life expectancy is consistently lower among Israeli Arabs than Israeli Jews [6]. Israeli studies have shown that Arabs develop heart failure and diabetes at a much younger age compared with their Jewish counterparts and have a higher prevalence of diabetes and obesity [7, 8]. Arabs in Israel generally have lower socioeconomic status than Jews, and more than $50 \%$ of the Arab population lives

(c) The Author(s). 2018 Open Access This article is distributed under the terms of the Creative Commons Attribution 4.0 International License (http://creativecommons.org/licenses/by/4.0/), which permits unrestricted use, distribution, and 
under the national poverty line [9]. Moreover, health literacy, a well-documented risk factor of poor health outcomes, has been shown to be disproportionally present in Arabs versus Jews, partly attributable to language barriers and to lower education levels [10]. Recent research has shown that while Arabs in Israel have poorer selfrated-health than Jews, this relationship is reversed when adjusting for socio-economic status and living environment [11], exemplifying the complex nature of the manifestation of health disparities.

Despite universal coverage and a national health insurance law in Israel since 1995, a wide-array of gaps in health care service use have been extensively documented, including, as also exemplified by Gal and colleagues [2], lower rates of specialist visits among Arabs than among Jews [12] and lower knowledge of attributes of the healthcare system, such as knowledge on supplementary health insurance [13]. For example, Reges and colleagues [14] show that ethnicity (Arab minority) is by far the most significant barrier to participation of patients with acute coronary syndrome in cardiac rehabilitation programs in Israel. Primary care use, on the contrary, has been shown to be higher among Arabs than Jews [12], which may reflect a pro-poor trend observed also in other countries [15].

The null findings regarding disparities in most of the indicators reported by Gal and colleagues [2] may reflect the indirect effect of the equity promoting mechanisms in the Israeli healthcare system, such as accessible and professional primary care services, which play a pivotal role in promoting equity in chronic disease management, and targeted programs to reduce disparities in primary care [16, 17]. A few additional Israeli studies have reported on lack of disparities or even on pro-minority differences in care between Arabs and Jews. For example, a study of the unwarranted epidemic of benzodiazepine use in Israel, found that older Arab Israelis are much less likely to receive benzodiazepine or benzodiazepine-receptor agonists than older Jewish Israelis [18]. A national Israeli study on participation in health promotion workshops has found that although participation rates among Arabs were lower than among Jews, once enrolled in a workshop, Arabs tended to attend more meetings than Jews [19].

However, it is not possible to rule out that the lack of disparities reported by Gal [2] and colleagues may be partly explained by limitations of the methodology used in that study. For example, Bago and colleagues suggest that more robust assessments that account for the individual variation over time may lead to identification of more pro rich distributions of physician utilization that can be otherwise observed [15]. Thus, utilizing additional individual covariates for which the analysis could have controlled (for example, general health status, number of additional comorbidities), could have led to the identification of gaps, which were not evident in the current analysis. Indeed, a previous study on health care utilization inequity in Israel has shown that using comprehensive health needs assessment measures allowed the study team to detect relative underutilization in use of specialist and diagnostic services, which could not be detected with less comprehensive forms of health-needs adjustments [20].

The lack of disparities reported by Feldman and colleagues [1] presents evidence for the lack of discrimination at the pediatric ED, contrary to findings on ethnic differences in ED waiting times from the US studies, which showed that Hispanic children and non-Hispanic black children had longer waiting times than nonHispanic white children [21, 22]. The study by Feldman and colleagues is noteworthy in that it controlled for the most pertinent potential confounders for a study of waiting times - time of arrival and triage level (an indicator of the need for urgent care).

Additionally, Feldman and colleagues address a potential reason for disparities in waiting times by differentially examining waiting times by ethnic concordance. Contrary to other studies, concordance between providers and patients was not related to differentiated waiting times. For example, in a study on patient-provider language concordance and the quality of transitional care in oncology patients at the same hospital (Rambam Medical Center), Rayan et al. report that language concordance was associated with higher ratings of the care transition experience by Arab and immigrant minority groups compared with the general Hebrew speaking population [23].

\section{Conclusion}

To conclude, the findings on the mainly lack of differences amongst Arabs and Jews in treatment of chronic comorbidities in schizophrenia patients [2] and in pediatric ED waiting times [1], reflect areas of equitable health care delivery within the Israeli healthcare system. These findings are at variance with the large body of literature that indicates the widespread disparities within the Israeli health care system.

The phenomena of health and healthcare disparities is complex and should utilize rigorous methodologies to account for the various factors that may affect the manifestation of differences amongst population groups. Rigorous methodology may help detect disparities which may otherwise be missed.

\section{Author's contribution}

ES reviewed the papers which this commentary is based on and wrote the commentary. The author read and approved the final manuscript.

Authors' information

ES, PhD, is an Associate Professor at the Cheryl Spencer Department of Nursing, Faculty of Social Welfare and Health Sciences, University of Haifa. ES 
also serves as a senior consultant to the Health Policy Planning department at the Chief Physician's office of Clalit Health Services and is the Co-editor-in-Chief of the International Journal for Equity in Health.

\section{Ethics approval and consent to participate}

This manuscript is a commentary and does not include any personal data therefore an ethics approval is not applicable.

\section{Competing interests}

The authors declares that she has no competing interests.

\section{Publisher's Note}

Springer Nature remains neutral with regard to jurisdictional claims in published maps and institutional affiliations.

Received: 27 February 2018 Accepted: 9 May 2018

Published online: 22 May 2018

\section{References}

1. Feldman O, Allon R, Leiba R, Shavit I. Emergency department waiting times in a tertiary children's hospital in Israel: a retrospective cohort study. Isr J Health Policy Res. 2017;6:60.

2. Gal G, Munitz H, Levav I. Double disparities in the health care for people with schizophrenia of an ethnic-national minority. Isr J Health Policy Res. 2017:6:47.

3. Whitehead M, Povall S, Loring B. The equity action spectrum: taking a comprehensive approach. Copenhagen: World Health Organization, Regional Office for Europe; 2014. http://www.euro.who.int/_data/assets/pdf_file/0005/ 247631/equity-action-090514.pdf?ua=1. Accessed 19 Feb 2018.

4. Starfield B. The hidden inequity in health care. Int J Equity Health. 2011;10:15.

5. Israel Central Bureau of Statistics. Statistical abstract of Israel 2015. 66 ed Jerusalem: Israel Central Bureau of Statistics; 2016 http://www.cbs.gov.il/ reader/shnaton/shnatone new.htm. Accessed 19 Feb 2018.

6. Muhsen K, Green MS, Soskolne V, Neumark Y. Inequalities in noncommunicable diseases between the major population groups in Israel: achievements and challenges. Lancet. 2017;389:2531-41.

7. Gotsman I, Avishai-Eliner S, Jabara R, Zemora Z, Shauer A, Lotan C, Keren A. Ethnic disparity in the clinical characteristics of patients with heart failure. Eur J Heart Fail. 2015;17(8):801.

8. Kalter-Leibovici O, Chetrit A, Lubin F, Atamna A, Alpert G, Ziv A, et al. Adultonset diabetes among Arabs and Jews in Israel: a population-based study. Diabet Med. 2012;29:748-54

9. Israel National Insurance Institute. The 2014 poverty report. Jerusalem: Israel National Insurance Institute; 2016. https://www.btl.gov.il/English\%20Homepage/ Publications/Poverty_Report/Documents/oni2014-e.pdf. Accessed 19 Feb 2018.

10. Levin-Zamir D, Baron-Epel OB, Cohen V, Elhayany A. The Association of Health Literacy with health behavior, socioeconomic indicators, and selfassessed health from a National Adult Survey in Israel. J Health Commun. 2016;21(Suppl 2):61-8.

11. Daoud N, Soskolne V, Mindell JS, Roth MA, Manor O. Ethnic inequalities in health between Arabs and Jews in Israel: the relative contribution of individual-level factors and the living environment. Int J Public Health. 2017; https://doi.org/10.1007/s00038-017-1065-3.

12. Rosen B, Israel MS. Health system review. Health Systems in Transition. 2009; 11:1-226. http://www.hpi.sk/cdata/Documents/HIT/Israel_2009.pdf. Accessed 19 Feb 2018

13. Green MS, Hayek S, Tarabeia J, Yehia M, HaGani N. A national survey of ethnic differences in knowledge and understanding of supplementary health insurance. Isr J Health Policy Res. 2017;6:12.

14. Reges O, Vilchinsky N, Leibowitz M, Khaskia A, Mosseri M, Kark JD. Identifying barriers to participation in cardiac prevention and rehabilitation programmes via decision tree analysis: establishing targets for remedial interventions. Open Heart. 2014;1:e000097.

15. Bago d'Uva T, Jones AM, van Doorslaer E. Measurement of horizontal inequity in health care utilisation using European panel data. J Health Econ. 2009;28:280-9

16. Spitzer-Shohat S, Shadmi E, Goldfracht M, Kay C, Hoshen M, Balicer RD Reducing inequity in primary care clinics treating low socioeconomic Jewish and Arab populations in Israel. J Public Health (Oxf). 2017;39:395-402.
17. Balicer RD, Hoshen M, Cohen-Stavi C, Shohat-Spitzer S, Kay C, Bitterman H et al. Sustained reduction in health disparities achieved through targeted quality improvement: one-year follow-up on a three-year intervention. Health Serv Res. 2015:50:1891-909.

18. Steinman MA, Low M, Balicer RD, Shadmi E. Epidemic use of benzodiazepines among older adults in Israel: epidemiology and leverage points for improvement. J Gen Intern Med. 2017;32:891-9.

19. Averbuch $E$, Avni S. Inequity in health and its management. Jerusalem: Ministry of Health; 2017. https://www.health.gov.l/PublicationsFiles/ inequality-2017.pdf. Accessed 19 Feb 2018

20. Shadmi E, Balicer RD, Kinder K, Abrams C, Weiner JP. Assessing socioeconomic health care utilization inequity in Israel: impact of alternative approaches to morbidity adjustment. BMC Public Health. 2011;11:609.

21. James CA, Bourgeois FT, Shannon MW. Association of race/ethnicity with emergency department wait times. Pediatrics. 2005;115:e310-5.

22. Park CY, Lee MA, Epstein AJ. Variation in emergency department wait times for children by race/ethnicity and payment source. Health Serv Res. 2009;44: 2022-39.

23. Rayan N, Admi H, Shadmi E. Transitions from hospital to community care: the role of patient-provider language concordance. Isr J Health Policy Res. 2014;3:24.

\section{Ready to submit your research? Choose BMC and benefit from:}

- fast, convenient online submission

- thorough peer review by experienced researchers in your field

- rapid publication on acceptance

- support for research data, including large and complex data types

- gold Open Access which fosters wider collaboration and increased citations

- maximum visibility for your research: over $100 \mathrm{M}$ website views per year

At BMC, research is always in progress.

Learn more biomedcentral.com/submissions 